\title{
TARGETING DRUG MEMORY RECONSOLIDATION: A NEURAL ANALYSIS
}

\author{
Ursule Taujanskaite', Emma N Cahill' and Amy L Milton²
}

'Department of Physiology, Development and Neuroscience, University of Cambridge, Cambridge, UK

2Department of Psychology, University of Cambridge, Cambridge, UK

\author{
Abstract: 93 words \\ Word count: 1774 words \\ Figures / tables: I \\ References: 56

\section{Corresponding author:} \\ Dr Amy L Milton \\ Department of Psychology \\ University of Cambridge \\ Downing Site \\ Cambridge
}

CB2 3EB

Tel: +44 I223333593

Email:alm46@cam.ac.uk 


\title{
HIGHLIGHTS
}

- Addiction is a disorder of maladaptive learning and memory.

- Different limbic corticostriatal regions support drug-associated memories.

- Disrupting drug-memory reconsolidation may provide a new addiction treatment.

- Regional manipulation makes specific aspects of drug memory tractable targets.

\begin{abstract}
Addiction can be conceptualised as a disorder of maladaptive learning and memory. Therefore, maladaptive drug memories supporting drug-seeking and relapse behaviours may present novel treatment targets for therapeutic approaches based upon reconsolidation-blockade. It is known that different structures within the limbic corticostriatal system contribute differentially to different types of maladaptive drug memories, including pavlovian associations between environmental cues and contexts with the drug high, and instrumental memories underlying drug-seeking. Here, we review the mechanisms underlying drug memory reconsolidation in the amygdala, striatum, and hippocampus, noting similarities and differences, and opportunities for future research.
\end{abstract}

\section{INTRODUCTION}

Addiction, a complex disease [I], can be conceptualised as a disorder of maladaptive memory [2,3] for which preventing relapse is the greatest challenge. Drug-associated memories might therefore provide a novel anti-relapse treatment target [4-6]. Disrupting drug-associated memories was not considered feasible until memory reconsolidation was rediscovered [7]. The prospect of modifying well-established memories raised the possibility that disrupting the memories driving relapse could be a novel pro-abstinence therapy. This view was supported by early studies showing that pharmacological agents ranging from protein synthesis and protein kinase inhibitors $[8,9]$ to $\beta$ adrenergic receptor antagonists $[\mathrm{I} 0, \mathrm{I} \mathrm{I}]$ reduced subsequent drug-seeking in rodents, if administered 
while the drug memory was 'reactivated' and unstable. This instability is usually achieved by briefly presenting discrete or contextual drug-associated conditioned stimuli (CSs) in the absence of drug or, less frequently, drug in the absence of associated CSs.

Any memory-modifying pharmacological treatment would need to be administered systemically in patients. However, understanding the neural mechanisms that support drug-associated memories remains important. We have previously reviewed how initially neutral environmental CSs (such as discrete cues, people, drug paraphernalia, contextual cues) become associated with drug highs in a pavlovian manner and subsequently increase drug-seeking [4]. Drug-seeking and drug-taking themselves are supported by instrumental memories that are initially goal-directed, associating the drug-seeking action with the drug-procurement outcome, but ultimately become habitual and driven by pavlovian CSs [12]. These memories are supported by different structures within the limbiccorticostriatal circuitry. Pavlovian CS-drug memories, particularly for discrete CSs, are represented within the amygdala, while the hippocampus is required for representing drug-associated contexts. Goal-directed and habitual memories are supported by different striatal regions, with a ventral-todorsal striatal shift as drug-seeking becomes habitual [12]. While all these regions contribute to drug-seeking behaviour and relapse, it cannot be assumed that the same plasticity mechanisms underlie memory persistence in all regions. We review the molecular and neurochemical mechanisms underlying drug memory reconsolidation in three key regions of the limbic corticostriatal circuitry: the amygdala, striatum, and hippocampus (Figure I).

\section{TARGETING THE RECONSOLIDATION OF PAVLOVIAN CUE-DRUG MEMORIES IN THE AMYGDALA}

The amygdala is essential for associating environmental CSs with the affective value of the drug unconditioned stimulus (US). The basolateral (BLA) and central amygdala (CeA) differ in their representation of drug-associated CSs and may be differentially required for the reconsolidation of 
memories induced by CS-based and US-based reactivation procedures [13]. As CS-drug memories are potent precipitators of relapse, both the BLA and CeA are logical targets for memory reconsolidation blockade [14].

The CeA appears engaged by US-based reactivation [15]. US-based alcohol memory reactivation leads to increased phosphorylation of S6 kinase (S6K), a critical component of the mammalian target of rapamycin (mTOR) pathway controlling mRNA translation (for review, see [16]) in the CeA, but not BLA [15]. Expression of excitatory transmission proteins, including Arc, PSD-95 and the GluAI subunit of AMPA receptors is also increased. These increases appear necessary for reconsolidation in the $\mathrm{CeA}$, as preventing $\mathrm{S} 6 \mathrm{~K}$ phosphorylation via upstream mTOR inhibition, concurrent with alcohol memory reactivation, prevented subsequent reinstatement of alcohol-seeking. Interestingly, this effect was specific to alcohol, not affecting sucrose memories. This suggests alcohol may recruit intracellular mechanisms, distinguishable from natural rewards, which may be specifically targeted.

More often reconsolidation-based interventions focus on the BLA, which represents the association between pavlovian CSs and specific outcomes [17]. As for US-based reactivation in the CeA, preventing mRNA translation in the BLA, concurrent with CS-based reactivation, disrupted drug memory reconsolidation [18]. Targeting intracellular pathways upstream of mRNA translation produces similar effects. The activation of protein kinases - or suppression of protein phosphatases - regulates mRNA translation, and several protein kinases in the BLA are necessary for CS-drug memory reconsolidation. Inhibiting protein kinase A (PKA) in the BLA during CS-based memory reactivation prevented both subsequent CS-induced and context-induced reinstatement [19-2I], though not drug-primed reinstatement [19]. At reactivation, activating Exchange Protein Activated by cAMP (EPac) with 8-pCPT-cAMP disrupted subsequent CS-induced reinstatement of cocaine seeking [22]. Furthermore, while increasing PKA-mediated signalling via 6-Bnz-cAMP did not enhance CS-drug memory reconsolidation [22], co-administration of 6-Bnz-cAMP with 8-CPT at reactivation 
rescued the deficit produced by activating EPac, suggesting antagonist feedback between the PKA and EPac pathways. Similarly, inhibiting another protein kinase, calcium-calmodulin-dependent kinase II (CaMKII), attenuated subsequent cue-induced reinstatement [23]. However, inhibiting CaMKII during CS-drug memory reactivation did not reduce subsequent context-induced cocaine seeking [20]. Overactivation of the calcium-triggered phosphatase calcineurin during reactivation inhibited both subsequent CS- and context-induced reinstatement of cocaine-seeking [24].

At the level of immediate early genes (IEGs), zif268 has been repeatedly implicated in drug memory reconsolidation. Knockdown of zif268 in the BLA before a CS-based reactivation decreased the acquisition of new, flexible cocaine-seeking [25] and cue-induced reinstatement of subsequent cocaine-seeking [26]. Upstream of Zif268 expression, antagonism of NMDARs in the BLA prior to memory reactivation not only prevented the acquisition of flexible cocaine-seeking, but also reduced the expression of Zif268 [27].

Taken together, the BLA and CeA seem differentially recruited by the use of context, discrete CSs and drug USs to reactivate the drug memory. Notably, the involvement of these regions in druginduced habitual responding changes with extended drug exposure. The BLA projects densely to the nucleus accumbens core, which itself projects to more dorsal striatal regions. With limited drug selfadministration, the pharmacological uncoupling of the BLA with the dorsolateral striatum reduced cocaine-seeking, whereas CeA manipulations had no effect until drug experience was extensive [28]. Therefore, we speculate that there may also be a BLA-to-CeA shift as drug experience becomes more extensive, and a consequent shift in the efficacy of CS-based and US-based reactivation procedures to destabilise the drug memory. 


\section{TARGETING THE RECONSOLIDATION OF PAVLOVIAN CUE-DRUG MEMORIES IN THE VENTRAL STRIATUM}

The striatum consists of ventral (nucleus accumbens core, NAcbC, and shell, NAcbSh) and dorsal substructures. The BLA projects densely to the $N A c b C$, and both the BLA and NAcbC are required for pavlovian CSs to influence instrumental responding [29]. As for the BLA, expression of zif268 increases in the NAcbC following cocaine CS exposure [30], and phosphorylation of specific proteins in the BLA and NAcbC is altered following CS-based drug memory reactivation [3I].

However, the NAcbC supports different aspects of the CS-drug memory to the BLA. Unlike the BLA [25], the reconsolidation of CS-drug memories supporting flexible cocaine-seeking does not require Zif268 in the NAcbC [32], even though NAcbC-BLA interactions are necessary for drugassociated conditioned reinforcers to support flexible cocaine-seeking [33]. Similarly, inhibiting ERK in the BLA, but not NAcbC, at reactivation impairs subsequent context-induced reinstatement of cocaine-seeking [34], though manipulations targeting the NAcbC consistently disrupt the reconsolidation of drug-conditioned place preference (CPP) memories $[8,9,32,35-38]$ and memories for approach to drug assessed using the runway procedure [39]. The NAcbC may be an important target for disrupting reconsolidation of general motivational properties of pavlovian CSs, alongside disruption of their sensory-specific properties by targeting the BLA.

\section{TARGETING THE RECONSOLIDATION OF CONTEXT-DRUG MEMORIES IN THE HIPPOCAMPUS}

The dorsal hippocampus (DH) is necessary for the representation of contextual information, and inactivation of the $\mathrm{DH}$ acutely impairs the context-induced reinstatement of drug-seeking [40]. The hippocampus has a well-established role in context-drug memory reconsolidation as measured by CPP [4 I-43]. For instrumental drug-seeking behaviour, the requirement for the hippocampus 
appears less straightforward. Inactivation of the DH with tetrodotoxin [44] or inhibition of GluN2Acontaining NMDARs or Src family kinases [45] prevents context-induced reinstatement in a reactivation-dependent manner. However, inhibiting protein synthesis with anisomycin does not [44]. Instead, protein synthesis inhibition in the BLA, coupled with contralateral inhibition of the DH in a 'disconnection' procedure, persistently reduced context-induced reinstatement [2I]. This likely indicates that although the $\mathrm{DH}$ is required to represent the contextual aspects of the context-drug memory, it is the BLA that stores the context-drug engram.

\section{TARGETING THE RECONSOLIDATION OF INSTRUMENTAL MEMORIES UNDERLYING DRUG-SEEKING IN THE DORSAL STRIATUM}

Drug-seeking and taking rely on instrumental memories. Instrumental learning recruits the dorsal striatum, with response-outcome (goal-directed) associations depending on the dorsomedial striatum (DMS), and stimulus-response (habitual) associations on the dorsolateral striatum (DLS) [46-49]. Originally, instrumental memories were thought not to reconsolidate [50]. However, this may have been due to unsuccessful memory destabilisation. Later studies disrupted instrumental memory reconsolidation by NMDAR antagonism with a change in reinforcement contingency at reactivation [5I,52], preventing subsequent stress-induced, though not CS-induced, relapse to cocaine-seeking [53]. While the NMDAR antagonist was administered systematically, we speculate that it may have affected dorsal striatal regions. This remains to be tested with local injections, or by assessing the effects of NMDAR antagonism on local reconsolidation markers such as Zif268 expression. However, it notable that knocking down zif268 in the posterior DLS during reactivation of a stimulus-response memory only transiently reduced habit-like behaviour on a T-maze task [54]. Whether this indicates that other IEGs are important for supporting the reconsolidation of instrumental memories, or other regions compensate for the loss of the memory in the posterior DLS, requires further investigation. 


\section{CONCLUSIONS}

Addiction is a disorder of learning and memory that presents many different psychological targets for disruption, including pavlovian and instrumental memories, and their interactions. Different regions support distinct aspects of drug-related memories, from the BLA supporting sensory-specific memories of drug CSs, the CeA contributing to US-based reactivation, the DH supporting contextual information, and the striatum supporting instrumental memories (Figure I). Though there are common principles regarding the molecular mechanisms underlying reconsolidation between these different regions - e.g. the recruitment of protein kinases and IEGs - it cannot be assumed that the mechanisms are identical between all structures. This may be particularly true for the relatively understudied (in the reconsolidation literature) GABAergic dorsal striatum. Further characterisation of reconsolidation mechanisms across brain structures would not only provide insight into the degree of conservation of plasticity mechanisms, but may also allow for systemic treatments to be used to target specific brain regions where a receptor or molecular pathway is uniquely associated with reconsolidation.

This review focused upon key structures within the limbic-corticostriatal circuitry, as they relate when drug-seeking is not yet compulsive. However, the progressively habitual and compulsive nature of drug-seeking in addiction leads to changes in the reliance on different structures within the limbiccorticostriatal circuitry [12]. While it is known that systems-level reconsolidation occurs between the hippocampus and the cortex [55,56], it remains unknown whether similar systems-level reconsolidation occurs, for example, between the BLA and CeA following extensive drug experience [28], or between different striatal regions as drug-seeking transitions from goal-directed to habitual. Coupled with potential differences in the molecular pathways supporting reconsolidation in different brain regions, changes in dependence on different parts of the limbic-corticostriatal circuitry could account for apparently dynamic boundary conditions. We suggest that in addition to characterising the molecular mechanisms of reconsolidation in different brain structures, research should focus on understanding how the memories that form the targets for reconsolidation-blockade move with time. 


\section{ACKNOWLEDGEMENTS}

ALM's research is funded by a UKRI MRC Programme Grant (MR/N02530X/I) awarded to Professors Barry J Everitt, Trevor W Robbins, Jeff W Dalley, Dr David Belin and ALM. ALM is the Ferreras-Willetts Fellow in Neuroscience at Downing College, Cambridge. ENC is currently receiving funding from Boehringer Ingelheim Pharma $\mathrm{GmbH} \&$ Co. for a project unrelated to this work. None of the funders had any involvement in the preparation, writing or submission of this review.

\section{AUTHOR CONTRIBUTIONS}

Ursule Taujanskaite: Conceptualisation; Investigation; Writing - Original Draft; Writing - Review and Editing. Emma N Cahill: Conceptualisation; Investigation; Writing - Original Draft; Writing Review and Editing; Supervision. Amy L Milton: Conceptualisation; Investigation; Writing Original Draft; Writing - Review and Editing; Visualisation; Supervision.

\section{REFERENCES}

[1] American Psychiatric Association (2013) The Diagnostic and Statistical Manual of Mental Disorders (5th ed.). American Psychiatric Publishing, Arlington, VA

[2] Everitt BJ, Dickinson A, Robbins TW (200I) The neuropsychological basis of addictive behaviour. Brain Research Reviews 36: 129-138.

[3] Hyman SE (2005) Addiction: a disease of learning and memory. American Journal of Psychiatry 162: $14 \mid 4-1422$.

[4] Milton AL, Everitt BJ (2010) The psychological and neurochemical mechanisms of drug memory reconsolidation: implications for the treatment of addiction. European Journal of Neuroscience 31: 2308-23I9.

[5] Milton AL, Everitt BJ (20I2) The persistence of maladaptive memory: addiction, drug memories and anti-relapse treatments. Neuroscience \& Biobehavioral Reviews 36: II I9-I I39.

[6] Torregrossa MM, Taylor JR (2013) Learning to forget: manipulating extinction and reconsolidation processes to treat addiction. Psychopharmacology 226: 659-672.

[7] Nader K, Schafe GE, LeDoux JE (2000) Fear memories require protein synthesis in the amygdala for reconsolidation after retrieval. Nature 406: 722-726. 
[8] Miller CA, Marshall JF (2005) Molecular substrates for retrieval and reconsolidation of cocaineassociated contextual memory. Neuron 47: 873-884.

[9] Valjent E, Corbillé AG, Bertran-Gonzelez J, Hervé D, Girault JA (2006) Inhibition of ERK pathway or protein synthesis during reexposure to drugs of abuse erases previously learned place preference. Proceedings of the National Academy of Sciences 103: 2932-2937.

[10] Bernardi RE, Ryabinin AE, Berger SP, Lattal KM (2009) Post-retrieval disruption of a cocaine conditioned place preference by systemic and intrabasolateral amygdala $b_{2}$ and $a_{1}$-adrenergic antagonists. Learning \& Memory 16: 777-789.

[I I] Milton AL, Lee JLC, Everitt BJ (2008) Reconsolidation of appetitive memories for both natural and drug reinforcement is dependent on $\beta$-adrenergic receptors. Learning \& Memory 15: 88-92.

[12] Everitt BJ, Robbins TW (2016) Drug addiction: updating actions to habits to compulsions ten years on. Annual Review of Psychology 67: 8.I-8.28.

[13] Besnard A, Caboche J, Laroche S (2012) Reconsolidation of memory: A decade of debate. Progress in Neurobiology 99:6I-80

[14] Exton-McGuinness MTJ, Milton AL (2018). Reconsolidation blockade for the treatment of addiction: challenges, new targets, and opportunities. Learning and Memory 25, 492-500.

[15] Barak S, Feng L, Ben Hamida S, Yowell QV, Kharazia V, Janak PH, Ron D (2013) Disruption of alcohol-related memories by mTORCI inhibition prevents relapse. Nature Neuroscience I6: I I I 1119

[16] Bevier A, Valjent E, Puighermanal E (2015) Ribosomal Protein S6 Phosphorylation in the Nervous System: From Regulation to Function. Front Mol Neuroscience 8:75

[17] Blundell P, Hall G, Killcross S (200I). Lesions of the basolateral amygdala disrupt selective aspects of reinforcer representation in rats. The Journal of Neuroscience, 21: 9018-9026

[18] Jian M, Luo Y-X, Xue Y-X, Han Y, Shi H-S, Liu J-F, Yan W, Wu P, Meng S-Q, Deng J-H, et al. 2014. elF2 $\alpha$ dephosphorylation in basolateral amygdala mediates reconsolidation of drug memory. The Journal of Neuroscience 34: 10010-10021

[19] Sanchez H, Quinn JJ, Torregrossa MM, Taylor JR (2010) Reconsolidation of a CocaineAssociated Stimulus Requires Amygdalar Protein Kinase A. J Neurosci: 30: 440I-4407.

[20] Arguello AA, Hodges MA, Wells AM, Lara H, Xie X, Fuchs RA. 20I4. Involvement of amygdalar protein kinase $A$, but not calcium/ calmodulin-dependent protein kinase II, in the reconsolidation of cocaine-related contextual memories in rats. Psychopharmacology (Berl) 23I: 55-65.

[2I] Wells AM, Lasseter HC, Xie X, Cowhey KE, Reittinger AM, Fuchs RA (20II) Interaction between the basolateral amygdala and dorsal hippocampus is critical for cocaine memory reconsolidation and subsequent drug context-induced cocaine-seeking behavior in rats. Learning and Memory 18(II): 396-702.

[22] Wan X, Torregrossa MM, Sanchez H, Nairn AC, Taylor JR. 20I4. Activation of exchange protein activated by CAMP in the rat basolateral amygdala impairs reconsolidation of a memory associated with self-administered cocaine. PLoS One 9: el 07359.

[23] Rich MT, Abbott, TB, Chung L, Gulcicek EE, Stone KL, Colangelo CM, Lam TT, Nairn AC, Taylor JR, Torregrossa MM (2016) Phosphoproteomic analysis reveals a novel mechanism of CaMKIl $\alpha$ regulation inversely induced by cocaine memory extinction versus reconsolidation. The Journal of Neuroscience 36(29): 76I 3-7627.

**[24] Rich MT, Huang YH, Torregrossa MM (2020) Calcineurin Promotes Neuroplastic Changes in the Amygdala Associated with Weakened Cocaine-Cue Memories. J Neurosci 40:1344-I 354 
The authors used behavioural, pharmacological and electrophysiological techniques to assess the impact of activating and inhibiting the protein phosphatase calcineurin on the reconsolidation and extinction of CScocaine memories.

[25] Lee JLC, Di Ciano P, Thomas KL, Everitt BJ (2005) Disrupting reconsolidation of drug memories reduces cocaine seeking behavior. Neuron, 47, 795-80I.

[26] Lee JLC, Milton AL, Everitt BJ (2006) Cue-induced cocaine seeking and relapse are reduced by disruption of drug memory reconsolidation. Journal of Neuroscience, 26, 588I-5887.

[27] Milton AL, Lee JLC, Butler V], Gardner R, Everitt BJ (2008). Intra-amygdala and systemic antagonism of NMDA receptors prevents the reconsolidation of drug-associated memory and impairs subsequently both novel and previously acquired drug-seeking behaviors. The Journal of Neuroscience, 28: 8230-8237.

[28] Murray JE, Belin-Rauscent A, Simon M, Giuliano C, Benoit-Marand M, Everitt BJ, Belin D (20I5). Basolateral and central amygdala differentially recruit and maintain dorsolateral striatum-dependent cocaine-seeking habits. Nature Communications, 6: 10088

[29] Everitt BJ, Parkinson JA, Olmstead MC, Arroyo M, Robledo P, Robbins TW (1999). Associative processes in addiction and reward. The role of amygdala-ventral striatal subsystems. Annals of the New York Academy of Sciences, 877, 4I2-438.

[30] Thomas KL, Arroyo M, Everitt BJ (2003). Induction of the learning and plasticity-associated gene Zif268 following exposure to a discrete cocaine-associated stimulus. European Journal of Neuroscience, 17(9), 1964-1972.

*[3I] Torregrossa MM, MacDonald M, Stone KL, Lam TKT, Nairn AC, Taylor JR (2019). Phosphoproteomic analysis of cocaine memory extinction and reconsolidation in the nucleus accumbens. Psychopharmacology, 236(I), 53I-543.

The authors assessed phosphoproteomic changes in the nucleus accumbens following the reconsolidation or extinction of a CS-cocaine memory, finding partially overlapping changes in protein phosphorylation.

[32] Théberge FRM, Milton AL, Belin D, Lee JLC, Everitt BJ (2010). The basolateral amygdala and nucleus accumbens core mediate dissociable aspects of drug memory reconsolidation. Learning and Memory, 17(9), 444-453.

[33] Di Ciano P, Everitt BJ (2004). Direct interactions between the basolateral amygdala and nucleus accumbens core underlie cocaine-seeking behavior by rats. Journal of Neuroscience, 24(32), 7I677173.

[34] Wells AM, Arguello AA, Xie X, Blanton MA, Lasseter HC, Reittinger AM, Fuchs RA. (20I3) Extracellular signal-regulated kinase in the basolateral amygdala, but not the nucleus accumbens core, is critical for context-response-cocaine memory reconsolidation in rats. Neuropsychopharmacology. 38:753-62.

[35] Li G, Wang Y, Yan M, Xu Y, Song X, Li Q, .. Wu Y (20I5). Inhibition of actin polymerization in the NAc shell inhibits morphine-induced CPP by disrupting its reconsolidation. Scientific Reports, 5.

[36] Li Y, Ge S, Li N, Chen L, Zhang S, Wang J, ... Wang X. (20I6). NMDA and dopamine DI receptors within NAc-shell regulate IEG proteins expression in reward circuit during cocaine memory reconsolidation. Neuroscience, 315, 45-69.

[37] Liang J, Li JL, Han Y, Luo YX, Xue YX, Zhang Y, ... Shi J (2017). Calpain-GRIP signaling in nucleus accumbens core mediates the reconsolidation of drug reward memory. Journal of Neuroscience, 37(37), 8938-895I. 
[38] Wu Y, Li Y, Gao J, Sui N (2012). Differential effect of NMDA receptor antagonist in the nucleus accumbens on reconsolidation of morphine -related positive and aversive memory in rats. European Journal of Pharmacology, 674(2-3), 32I-326.

[39] Crespo JA, Stöckl P, Ueberall F, Jenny M, Saria A, Zernig G (20I2). Activation of PKCzeta and PKMzeta in the nucleus accumbens core is necessary for the retrieval, consolidation and reconsolidation of drug memory. PLoS ONE, 7(2).

[40] Fuchs RA, Evans KA, Ledford CC, Parker MP, Case JM, Mehta RH, See RE (2005) The role of the dorsomedial prefrontal cortex, basolateral amygdala, and dorsal hippocampus in contextual reinstatement of cocaine seeking in rats. Neuropsychopharmacology 30(2): 296-309.

[4I] Taubenfeld SM, Muravieva EV, Garcia-Osta A, Alberini CM (20I0) Disrupting the memory of places induced by drugs of abuse weakens motivational withdrawal in a context-dependent manner. Proceedings of the National Academy of Sciences 107(27): I2345-I 2350.

[42] Otis JM, Fitzgerald MK, Mueller D (20I4) Inhibition of hippocampal $\beta$-adrenergic receptors impairs retrieval but not reconsolidation of cocaine-associated memory and prevents subsequent reinstatement. Neuropsychopharmacology 39(2): 303-310.

*[43] Liu C, Sun X, Wang Z, Le Q, Liu P, Jiang C, Wang F, Ma L (2018) Retrieval-induced upregulation of Tet3 in pyramidal neurons of the dorsal hippocampus mediates cocaine-associated memory reconsolidation. International Journal of Neuropsychopharmacology 21 (3): 255-266.

The authors examined the effects of chemogenetically inactivating neurons in the dorsal hippocampus during the reconsolidation of the memory underlying cocaine CPP. They found that the subsequent impairment in place preference correlated with an increase in expression of the epigenetic modulator Tet3 observed in a separate group of animals. They then showed the necessity of Tet3 for the reconsolidation of the cocaine CPP memory by knocking down Tet3 during reactivation to observe a long-term memory deficit.

[44] Ramirez DR, Bell GH, Lasseter HC, Xie X, Traina SA, Fuchs RA (2009) Dorsal hippocampal regulation of memory reconsolidation processes that facilitate drug context-induced cocaine-seeking behavior in rats. European Journal of Neuroscience 30(5): 90I-912.

[45] Wells AM, Xie X, Higginbotham JA, Arguello AA, Healey KL, Blanton M, Fuchs RA (2016) Contribution of an SFK-mediated signaling pathway in the dorsal hippocampus to cocaine-memory reconsolidation in rats. Neuropsychopharmacology 4 I (3): 675-685.

[46] Murray JE, Belin D, Everitt BJ (2012). Double dissociation of the dorsomedial and dorsolateral striatal control over the acquisition and performance of cocaine seeking. Neuropsychopharmacology, 37(II), 2456-2466.

[47] Shiflett MW, Brown RA, Balleine BW (2010). Acquisition and performance of goal-directed instrumental actions depends on ERK signaling in distinct regions of dorsal striatum in rats. Journal of Neuroscience, 30(8), 295I-2959.

[48] Yin HH, Knowlton BJ, Balleine BW (2005). Blockade of NMDA receptors in the dorsomedial striatum prevents action-outcome learning in instrumental conditioning. European Journal of Neuroscience, 22(2), 505-5I2.

[49] Zapata A, Minney VL, Shippenberg TS (2010). Shift from Goal-Directed to Habitual Cocaine Seeking after Prolonged Experience in Rats. Journal of Neuroscience, 30(46), I5457-I5463.

[50] Hernandez PJ, Kelley AE (2004). Long-term memory for instrumental responses does not undergo protein synthesis-dependent reconsolidation upon retrieval. Learning and Memory, I I (6), 748-754. 
[5I] Exton-McGuinness MTJ, Patton RC, Sacco LB, Lee JLC (20I4). Reconsolidation of a well-learned instrumental memory. Learning and Memory, 2I(9), 468-477.

[52] Tedesco V, Mutti A, Auber A, Chimulera C (2014) Nicotine-seeking reinstatement is reduced by inhibition of instrumental memory reconsolidation. Behavioural Pharmacology 25(8): 725-73I.

**[53] Exton-McGuinness MTJ, Drame ML, Flavell CR, Lee JLC (2019). On the Resistance to Relapse to Cocaine-Seeking Following Impairment of Instrumental Cocaine Memory Reconsolidation.

Frontiers in Behavioral Neuroscience, 13.

Developing their previous research examining the reconsolidation of instrumental memories, the authors showed that disrupting the reconsolidation of cocaine-seeking memories with the NMDAR antagonist MK$80 \mathrm{I}$ led to a reduction in cocaine-seeking at subsequent test, but only if cocaine-associated CSs were not presented. Furthermore, while disrupting the reconsolidation of the instrumental memory reduced subsequent stress-induced reinstatement of cocaine-seeking, it did not impair drug-induced reinstatement.

*[54] Cahill EN, Vousden GH, Exton-McGuinness MTJ, Beh IRC, Swerner CB, Macak M, ... Milton AL (2018). Knockdown of zif268 in the Posterior Dorsolateral Striatum Does Not Enduringly Disrupt a Response Memory of a Rewarded T-Maze Task. Neuroscience, 370, II2-120.

Using a T-maze task to separate goal-directed and stimulus-response behaviours, the authors found that knockdown of the immediate early gene Zif268 in the posterior dorsolateral striatum prior to memory reactivation led to a transient reduction in stimulus-response behaviour at test.

[55] Debiec J, LeDoux JE, Nader K (2002) Cellular and systems reconsolidation in the hippocampus. Neuron 36(3): 527-538.

[56] Wang S-H, de Oliveira Alvares L, Nader K (2009) Cellular and systems mechanisms of memory strength as a constraint on auditory fear reconsolidation. Nature Neuroscience 12(7): 905-912.

\section{FIGURE LEGEND}

Figure I. (a) Sagittal section of the rat brain, with key locations implicated in drug memory reconsolidation highlighted. (b) Schematic of major connections between brain regions implicated in drug memory reconsolidation, indicating the aspect of the drug memory encoded by each region. The type of memory reactivation protocol that appears effective at recruiting each region is noted in brackets. Abbreviations: Amy, amygdala; DH, dorsal hippocampus; DS, dorsal striatum; NAcb, nucleus accumbens. 
a

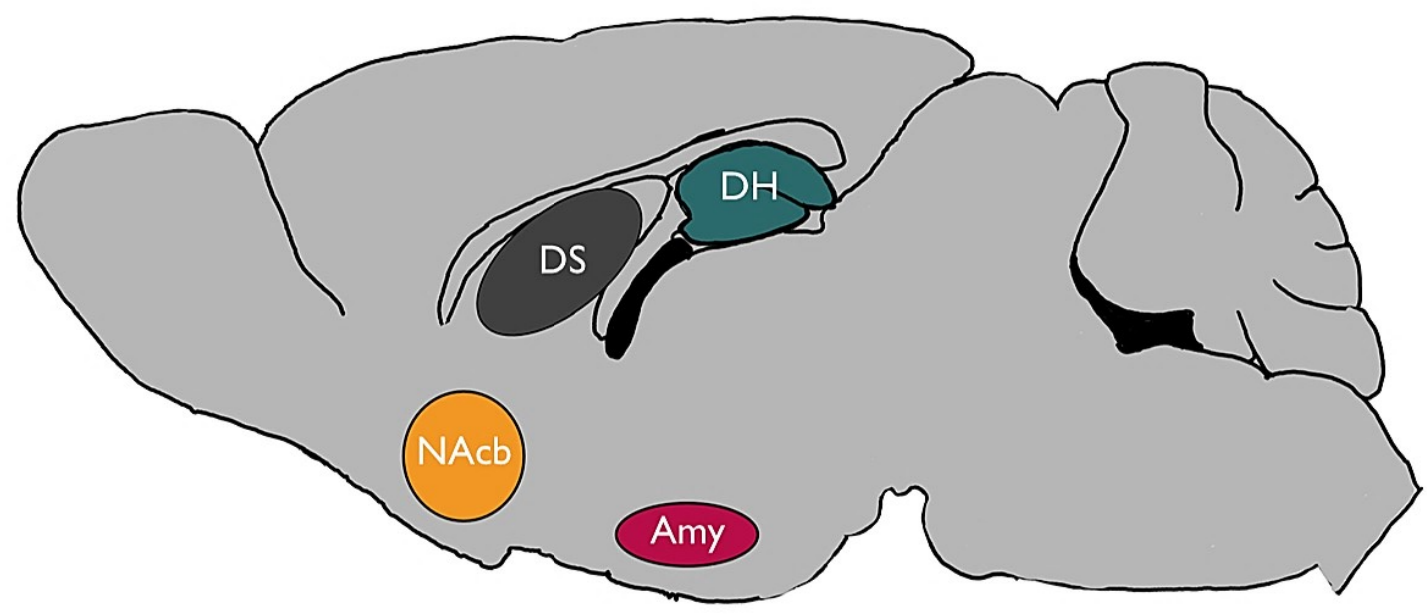

b

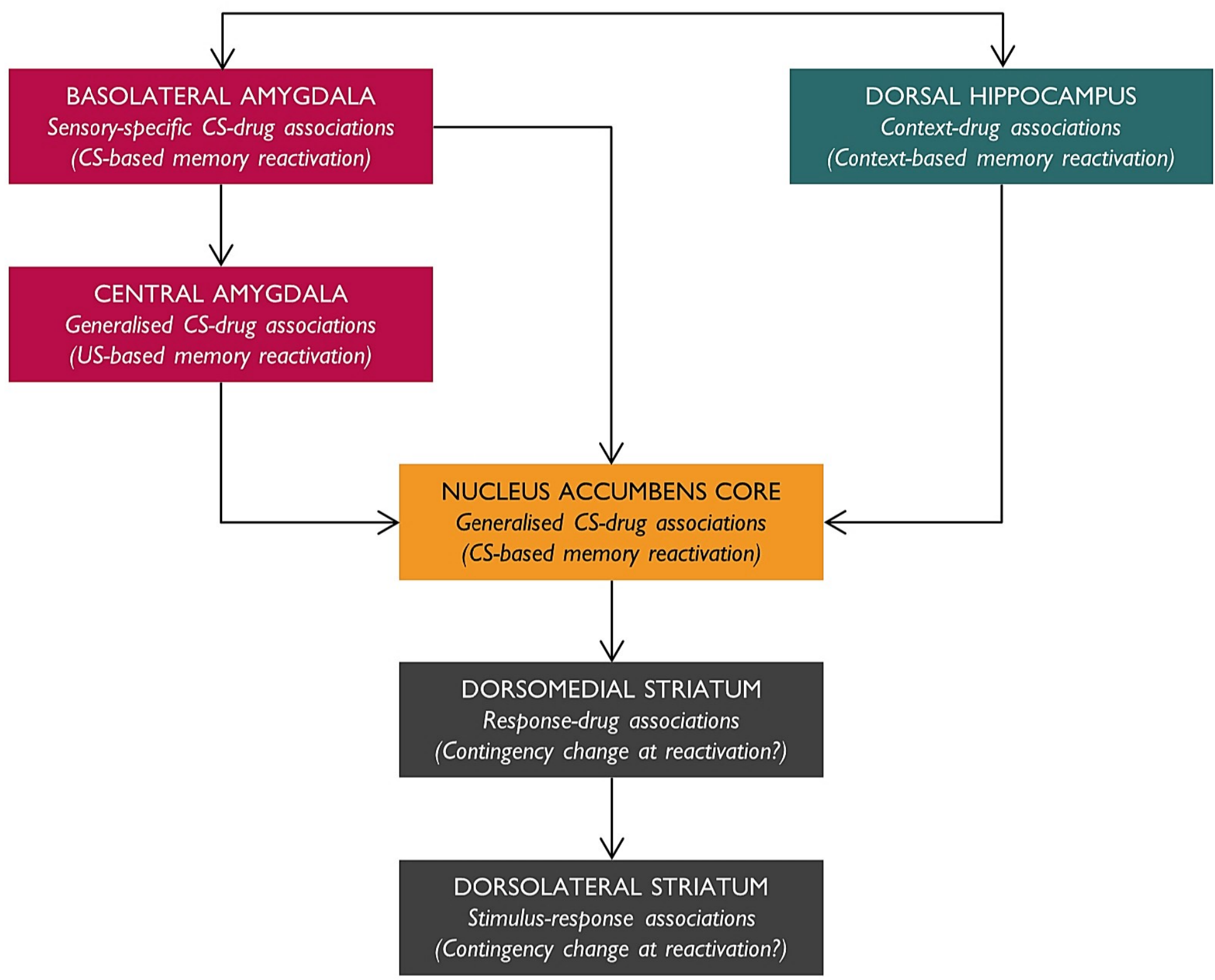

